Experimental and simulation analysis on multi-gate variants in sand casting process

I. Rajkumar ${ }^{1}$, N. Rajini ${ }^{1}$ *, A. Alavudeen ${ }^{1}$, T. Ram Prabhu' ${ }^{2}$, S. O. Ismail ${ }^{3}$, Faruq Mohammad ${ }^{4}$, Hamad A. Al-Lohedan ${ }^{5}$

${ }^{1}$ Department of Mechanical Engineering, International Research Centre, Kalasalingam Academy of Research and Education 626126, India.

${ }^{2}$ Deputy Director / Scientist, Materials and Manufacturing Engineering for Aerospace Applications, Defence R\&D Organization, Bangalore.

${ }^{3}$ Centre for Engineering Research, Department of Engineering, School of Physics, Engineering and Computer Science, University of Hertfordshire, AL10 9AB, England, UK.

${ }^{4,5}$ Department of Chemistry, College of Science, King Saud University, P.O. Box 2455, Riyadh, Kingdom of Saudi Arabia 11451.

*Corresponding author: N. Rajini, rajiniklu@gmail.com, Department of Mechanical Engineering, Kalasalingam Academy of Research and Education, Krishnankoil 626 126, Tamil Nadu, India. Tel.: +91 9942139392. 


\title{
Experimental and simulation analysis on multi-gate variants in sand casting
}

\section{process}

\begin{abstract}
This present work proposes an improved multi-gate designs (MGDs) in sand casting process, using both experimental and simulation (FLOW 3D) approaches, aiming to produce defect-free component. In this regard, the variant MGDs were developed and compared with the existing designs reported in the previous studies. Accordingly, the following new MGDs: side sprue serial connection (SSSC), centre sprue serial connection (CSSC), side sprue parallel connection (SSPC), centre sprue parallel connection (CSPC) and centre sprue runner extension parallel connection (CS-RE-PC) were modelled for both techniques. The experimental set-ups were developed for the aforementioned designs to study the flow behaviour of aluminium alloy and water. The validity of aluminium alloy flow characteristics in closed mould condition was checked with the water mould experimentation. The quality of the casting was examined by visual inspection, optical microscopy, ultrasonic and X-ray tests. From the results obtained, it was evident that CS-RE-PC mould set-up or design was most suitable with a runner system for four-cavity application. This design exhibited best flow rate, as a nearly defect-free casting component was produced. Comparison of the FLOW 3D simulation results with similar experimental findings provided potential opportunity to reduce both cast product rejection rate and rework, and consequently it aids enhancement of the productivity and profitability in a manufacturing/casting industry.
\end{abstract}

KEYWORDS: Casting; liquid aluminium alloy/metal; water; multi-gate system; experimental and simulation; defects. 



\section{Introduction}

The gate system is a significant component of a casting process. It carries liquid metal from ladle to mould cavity. Liquid metal passes through various parts, such as spurs, main runner, sub runner and gate (Fig. 1). A faultless gate design ensures proper filling, it prevents from the minimisation of misruns, cold short, turbulence, air entrainment and gas porosity defects [1]. A small casting process prefers single sprue and single in-gate, using in single cavity, while a mass production attracts multi-cavity. Also, a large casting prefers multi-sprue runner and more than one sprue. The main objectives of a good gate system design, as applied to this investigation, are to eliminate trial and error runner method, predict complex multi-gate system easily, achieve an active uniform filling of all components and maintain constant pressure head [2].

Fig. 1. Basic components of a classic gating structure.

Most of the well-designed gate systems have vertical sprue, horizontal runner and gate. Large casting often requires multiple sprues, runners and gate [3]. Recently, several casting industries are expecting higher productivity through the implementation of multi-cavity mould systems [4]. The number, shape, size and quality of the cast products significantly depend on changes in design, uniform filling at a reduced volume of a gate system. The mould filling time (metal flow rate) is controlled by small effective cross section, referred to as a bottom of sprue or the gates $[5]$.

In addition, runner ratio plays a major role in a flow rate which depends on geometry of gate system, accordingly it may either converges or diverges the metal flow [6]. Casting quality is a function of casting, size, shape, dimension of gating channel and perfect flow parameters. However, it is difficult to find or predict flow sequence, velocity, distribution and discharge of the various gate flows in some multi-gate components. Therefore, several experimental 
investigations have been carried out to consider multi-gate designs (MGDs), using aluminium and water as flow media. In this regard, a study reported the flow of fluid in a multi-gate system, including identification of flow rate and velocity [7]. In addition, the efforts have been taken on the development of mathematical and simulation models to forecast the flow rate in a single gate and multi-gate systems. One of them was compared with the flow rate of molten metal in gate with sprue. This study involved numerical and experimental methods, with a horizontal multigate system runner with a constant cross section over the length [8].

Moving forward, the sand casting process across the world suffers expensive tooling, long lead time and less flexibility, difficult to identify perfect pattern makers of single cavity and multi-cavity applications. These drawbacks reduce production quantity, support many number of defects. From the investigation, it was conclusively reported that the sprue location and shape were major determining factors in casting quality [9]. Also, the aforesaid problems can be resolved using optimised feeder system by means of avoiding trial and error based manufacturing through appropriate selection of gate and sprue location [10]. The optimised feeder was similarly used to obtain a smooth and even filling sequences. Therefore, it produced a good quality casting [11]. More also, numerical simulation and experimental results have been obtained to predict critical component gate system and sprue arrangement [12]. The simulation results predicted porosity defect and filling sequence in bottom and vertical gate systems [13]. Identification of multi-cavity flywheel, brake disk metal flow and solidification behaviour of a cast part were simulated, using FLOW 3D simulation software [14]. Several studies have reported that up to $90 \%$ of the total casting defects were caused by an improper gate and runner system. However, application of simulation software has minimised these defects to $30 \%$. This was validated, using ultrasonic test method [15]. 
Furthermore, several state-of-the-art research works have been carried out experimentally and numerically to achieve the sustainable quality of casting products, through effective implementations of scientific findings. Recently, a systematic framework was proposed for the selection of appropriate gating system in sand casting process based on the results obtained from the computational fluid dynamics (CFD) simulations with respect to air entrainment, surface defect concentration and mould cost [16]. Ingle et al. [17] carried out a comprehensive review, which demonstrated various gating systems, numerical tools and the flow parameters more specifically with their effects on the casting defect minimisation. Moreover, the review also presented that though there were many numerical investigations carried out to simulate casting process; still there is a scope to map the numerical validation more realistic with experimentation. Zheng et al. [18] studied the application effectiveness of new technologies on the resource mobilisation, environmental and productivity in the traditional sand casting manufacturing industries. From their analysis, a magnificent improvement was observed in all the aforementioned aspects by means of introducing additive and subtractive manufacturing technologies on the casting process. This emphasised the practical importance of adapting new approaches in the conventional model.

More also, recent study has reported the idea that sand casting process parameters can be studied in the design phase to minimise the time and resource wastage. Accordingly, carbon emission model was developed to discover the optimisation of schemes in three aspects: structure, gating system and process parameters. From the predictive analysis model, the gating system parameters optimised process was observed to possess a largest proportion of recyclable resources, which assisted to attain the sustainable development of conventional casting industries in long term process [19]. 
Besides, many numerical simulation works have been carried out for various other casting processes. Barot and Ayar [20] studied the defect identification of variant geometry, using AUTOCAST - XI numerical software for mould gravity casting process. The shrinkage porosity was measured in both experimental and numerical methods for different plate thickness and observed a minimum variation at maximum thickness. Additionally, several recent studies have suggested improvement of quality products to different casting industries through validation of experimental/numerical models, using various software with defined constraints based on the type of processes [21-23].

From the above literature reviews, it was evident that the demand for the experimentation and numerical analysis is still required towards transformation of automation in sand casting industries. As earlier stated, the gating design is one of the important factors, which can be explored further through scattered geometries with respect to minimise the quantification of defects. Therefore, this present investigation focuses on the production of samples, using variant MGDS in sand casting process. Besides, the simulation results were validated using experimental approach. Both aluminium alloy and water were used as the source medium to predict the flow patterns. Two existing designs studied were used to design experimental investigation required to study the aluminium alloy used in this current work. The water mould was developed by acrylic sheet in order to observe the velocity and mass flow rate through transparent visuals. Also, three dimensional (3D)-printed patterns were developed with proper allowances for both open and closed mould conditions. The velocity and mass flow rate were measured by open mould and various casting defects were identified after producing components in closed mould set-ups. Microscopic inspection of the associated manufacturing (casting) defects was carried out, using visual, optical microscopy, ultrasonic and X-ray methods. 


\section{Materials and experimental methods}

\subsection{Materials used}

Generally, ferrous and non-ferrous materials show differences in all their flow parameters; however non-ferrous materials show slightly a less variation. For instance, aluminium alloys comparatively possess a very minimum flow variation when compared with other materials. In this work, a LM4(Al-Si5Cu3) material was used and its flow parameter was more or less equal to that of LM6(Al-Si12). The flow parameters are one of the critical factors to decide the casting quality. This necessitated the main objective of comparing previous study with this present work.

\subsection{Existing and new MGDs}

Two existing designs namely, side sprue serial connection (SSSC) and side centre sprue serial connection (CSSC) studied in the previously published paper were considered for the experimental analysis of flow of the new molten metal. In these designs, a single vertical sprue was connected with the long horizontal runner in which all the four components were connected in series for SSSC, and two components are placed in left and right sides of the sprue equally for CSSC. Similarly, the geometry of same designs was used for the numerical analysis and to discuss the comparison of results obtained with the other designs to be considered in this work. It is known that the orientation of the component and gate location play a major role in casting quality. The modified designs have same sprue dimensions, gate and runner cross section, but different gate location. The gates were arranged in opposite manner; therefore, length of the runner was reduced and comparatively modified to produce design with a higher yield percentage. Summarily, the following design patterns were employed: 
1. Vertical tapered sprue on one side of the horizontal runner, which was connected to four gates arranged in parallel form - Side sprue parallel connection (SSPC).

2. Vertical tapered sprue coupled centre to the horizontal runner, which was connected to four gates in parallel arrangement - Centre sprue parallel connection (CSPC).

3. Vertical tapered sprue was coupled with one side of the extension of vertical runner, which in turn connected horizontal runner and followed to four gates in parallel direction - Centre sprue runner extension parallel connection (CS-RE-PC).

For all the designs, the cross-sections of runner of $15 \mathrm{~mm}$ x $15 \mathrm{~mm}$ and gate of $18 \mathrm{~mm} \times 9$ $\mathrm{mm}$ were used, with a gate ratio of 1:2:5.6. The dimensions of runner and gate were similar to metal and water flow moulds. But, the metal and water flow moulds were created by sand and transparent acrylic sheet, respectively. The modified 2D and 3D diagrams of MGDs, such as SSPC, CSPC and CS-RE-PC were developed by using AutoCAD and Creo 3.0 software packages, as depicted in Fig. 2.

Fig. 2. Development of 2D and 3D casting models for different MGDs, using AutoCAD and Creo 3.0 software.

\subsection{Experimental set-up}

The sand casting experimental set-up was prepared in two conditions: (a) open mould and (b) closed mould to obtain the final components from the four cavity system. The open mould experiment set-up was performed, coupled with the facility of video capturing to identify the sequence of filling and other flow parameters for different media inside the cavity. The patterns were developed using 3D printing plastic material for all their casting geometry. 3D-printed patterns were mainly chosen, considering the known fact that the better dimensional accuracy and higher surface finish can be achieved with plastic material when compared with the 
conventional wooden and wax patterns. Figs 3(a) and (b) show the photographic images of entire 3D printed sand casting pattern for CSPC and the runner with gate system for SSPC.

Fig. 3. (a) CSPC and (b) SSPC plastic patterns developed by 3D printing.

The mould was maintained at $100-150{ }^{\circ} \mathrm{C}$ superheat in sand casting process. The aluminium alloy was heated until the kinematic velocity of the pouring molten metal similar to that of water was obtained. The experiments were conducted by using the flow set-ups in a multi-gate system, as shows in Fig. 4. Therefore, all the five MGD casting components were fabricated in three times with 20 components in each trail and with the total number of 60 components, as a whole. Due to the experimental design, three types of results were obtained: sequence of flow through different gates, velocity and volume flow rates through each gate. These results were extensively and subsequently discussed.

Furthermore, defect analysis was performed to identify the various casting defects, such as shrinkage porosity, pin holes, internal and external holes with the aid of different efficient testing methods. Detailed discussions on inspection of associated defects are subsequently presented before conclusive remarks.

Fig. 4. Experimental set-up of sand casting process with open and closed moulds for different MGDs: (a) SSSC, (b) CSSC, (c) SSPC, (d) CSPC and (e) CS-RE-PC.

\subsection{Analytical method}

The water mould experimentation was mainly performed to govern the interior flow characteristics of molten alloy in closed mould set-up through transparent visualization. It was observed that the kinematic viscosity of aluminium alloy at pouring temperature can be 
approximately equivalent to that of water, as described in the previous study [3]. Accordingly, the water mould set-up was modelled using SolidWorks software and then followed with the fabrication of acrylic sheet, according to the defined geometry for all the three modified MGDs.

Fig. 5. Water mould experiment set-ups for various MGDs.

The water model set-ups (Fig. 5) were manufactured by acrylic fabrication. There were sump and pump arrangements to circulate the water. Provision of an overflow exit was included to maintain water level in the top basin. Mesh block was adapted to decrease the turbulence induced by the pump. The gates were covered with a flap. The flap was only opened, provided a steady head has been observed in the pouring basin. The gate was closed before pouring the water, before it was later opened after a certain steady head was reached. From the experimentation of water mould set-up, various flow information such as the sequence of filling, fluid velocity and volume of flow rate were measured for all the MGDs including the existing reference designs. Table 1 presents process parameters and properties for both water and aluminium alloy used.

Table 1. Parameters of aluminium alloy and water materials used.

For the practical purpose, the trajectory of molten alloy and water from the exit of gating to the cavity was governed as a moving object, such as a projectile. Hence, the motion of the particle at any instance can be studied with the combination of horizontal and vertical motions. Therefore, the non-zero initial velocity was assumed to be obtained from the pouring of alloy and/or water. In addition, all the kinematic parameters of the flow of particles were calculated, considering the constant velocity condition for horizontal direction and uniform acceleration condition for vertical motion. The schematic model of liquid flow from the experimental set-up 
is shown in Fig. 5, with the markings of all the relevant parameters to be considered for the analytical formulations.

The flow velocity was determined, using Eq. (1) [3].

$$
\mathrm{V}=\sqrt{(2 \mathrm{gh})}
$$

Where, $\mathrm{V}, \mathrm{h}$ and $\mathrm{g}$ represent flow velocity, pressure head (sum of height of sprue and fluid level in the pouring basin) and gravity casting, respectively. According to the water model feeding system, cavity should make a steady-state flow of metal in the corresponding sandmoulded gate system and cavity, provided the Reynolds numbers in the two cases are nearly equal.

The horizontal range between the exit of gate and the point of flow impact in the cavity can be calculated by applying the uniform velocity condition in the kinematic equations for uniformly accelerated motion; using Eq. (2).

$$
\mathrm{R}=\mathrm{V}_{\mathrm{h}} \mathrm{t}_{\text {flight }}
$$

Where $R$ denotes the horizontal distance and the quantity of $R$ was obtained from the experiments. $V_{h}$ represents the horizontal component of the impact velocity. The flight time, $t_{f l i g h t}$ was determined by using Eq. (3), where $h_{j}$ and $g$ stand for vertical fall height and gravity, respectively.

$$
t_{\text {flight }}=\sqrt{\frac{2 \mathrm{~h}_{\mathrm{j}}}{\mathrm{g}}}
$$

The value of $R$ was used to determine the horizontal component of flow velocity through gate, $V_{h}$ (=Rtflight before the impact) as in Eq. (4). 


$$
V_{h}=R \sqrt{\frac{g}{2 h_{j}}}
$$

Vertical component of flow velocity through gate, $V_{v}$ was determined, using Eq. (5).

$$
V_{\mathrm{v}}=\sqrt{2 g} \mathrm{~h}_{\mathrm{j}}
$$

The resultant of horizontal and vertical components of gate velocity produced the impact velocity, $V_{\text {impact }}$ of jet, using Eq. (6).

$$
V_{\text {impact }}=\sqrt{V_{v}^{2}+V_{h}^{2}}
$$

The horizontal range of flow projectile was determined based on the trajectory of molten alloy/water with the help of measuring scale placed on top of the mould. Furthermore, the point of impact can be mapped with the measuring scale through the recorded video from the highdefinition camera fitted into the experimental set-up. Also, time of flight, flow velocity through each gate and impact velocity of the mould were determined according to the trajectory of flow depicted in Fig. 5.

\subsection{Numerical simulation}

All the models were developed using FLOW 3D software. It was used to simulate multicavity casting, using aluminium alloy (LM4) material. Multi-cavity filling sequence was observed, which was expected to be changed based on the geometry of the runner system. FLOW 3D simulation analysis was done with the assumptions of uniform metal entry, even filling with the expectations of obtaining quality in the cast products. In addition to all the MGDs: SSPC, CSPC and CS-RE-PC, the previously reported designs; namely SSSC and CSSC 
were also considered to understand the flow behaviour and for the comparison purpose. FLOW 3D modelling programmes were used in this research to conduct the simulation of four cavities and five mould techniques. Cast alloy and boundary conditions must be selected to simulate precise casting mould content.

3D models of five mould set-ups were generated, using Creo software; their computer-aided design (CAD) files were translated to stereolithography (STL) files and then inserted into FLOW 3D simulation application. While importing, highest priority was given to cast object, then to runner and gating system. Casting and feeding systems were then installed. Molten metal was poured into each mould set-up in z-position on sprue top. Model was meshed using suitable node size, and simulation was run with the FLOW 3D software, using some flow input parameters, as stated in Table 2.

Table 2. The flow input parameters.

\section{Results and discussion}

\subsection{Analytical findings}

The results of aluminium alloy filling in SSSC set-up were plotted in Fig. 6(a), as a replica of the simulation results, the lowest gate velocity was obtained in G1 component nearest sprue and terminated when metal was filled. The highest gate velocity was obtained in a farthest component G4 from the sprue and thereby metal filling was initiated. The gate velocity has a range of $\mathrm{G} 1<\mathrm{G} 2<\mathrm{G} 3<\mathrm{G} 4$ and the same sequence was shown in LM4 material. The velocity of filling in CSSC set-up depicted that both first and last components were approximately equal $(\mathrm{G} 1=\mathrm{G} 4)$, as shown in Fig. 6(a). The second and third components nearly exhibited equal filling $(\mathrm{G} 2=\mathrm{G} 3)$ and the filling sequence followed $\mathrm{G} 2=\mathrm{G} 3<\mathrm{G} 1=\mathrm{G} 4$. 
Fig. 6. Metal flow velocities of (a) SSSC and (b) CSSC.

In the case of SSPC, all the components were arranged in opposite direction and equal distance on one side sprue, the filling sequence showed similar results for both water and alloy. The velocity of component filling and entry sequence approximately followed $\mathrm{G} 3=\mathrm{G} 4>\mathrm{G} 1=\mathrm{G} 2$, as shown in Figs 7(a) and (b).

Fig. 7. Water flow velocities of (a) SSPC, (b) CSPC and (c) CS-RE-PC as well as metal flow velocities of (d) SSPC, (e) CSPC and (f) CS-RE-PC.

In CSPC, sprue was arranged at the centre of runner of both components in parallel form. The fillings of metal and water were approximately equal in the components and velocity, as shown in Figs 7(a) and (d). The CS-RE-PC set-up in which sprue was kept away from runner, located at centre thereby exhibited approximately equal filling and sequence of $\mathrm{G} 1=\mathrm{G} 2=\mathrm{G} 3=\mathrm{G} 4$ in water flow velocity, as shown in Fig. 7(e). The velocity of component filling and sequence approximately followed G3=G4>G1=G2 (Fig. 7(f)), similar to that of SSPC.

Measuring the volume of fluid to determine average discharge or flow rate required collection of flow in each cavity at a given time. The flow was stopped when one of the cavities (the last one) was nearly filled, then time was recorded. The relative amounts of flow in different cavities using two fluids (water and alloy) were determined, and volumes were calculated after solidification of the metal. It was carried out thrice to find average volume. It was evident that water recorded higher kinematic viscosity when compared with the aluminium metal. With the SSSC, the velocities of last two components were closer, but flow rates were comparatively dissimilar. The CSSC has the G1 and G4 as well as G2 and G3 components of velocities and 
flow rates differed, but G1 and G4 as well as G2 and G3 component volumes and flow rates were approximately equal (Table 3). The SSPC components were arranged in a parallel and equal distance, velocities and flow rates for G1 and G2 as well as G3 and G4 components were similar, but in-between first two and next two components were equal filling (Tables 4 and 5).

Table 3. Existing mould design for metal flow rate of aluminium alloy.

Table 4. Water flow rate of modified runner design.

Table 5. Existing and Modified runner design for the metal flow rate.

For the CSPC and CS-RE-PC designs, four component velocities were more or less equal, but minimum flow rates were recorded in CS-RE-PC (Table 5). It appeared trivial to establish an acceptable relationship for evaluating the gate velocity. The overall trend was observed to be same as velocity, and average flow rate through the farthest component from the sprue was higher, but lower from the nearest gate from sprue. It resulted to inertial effects; the fluid struck the end of the runner and flowed backward, due to pressure and/or stagnation, which pushed the fluid to the nearest component in both materials.

\subsection{Simulation results}

The SSSC design exhibited an uneven filling sequence in the four components. The first and last casting components with G1 and G4 were uniformly filled with metal flow faster than other two casting components with G2 and G3 in CSSC set-up, as shown in Fig. 8. Later, the components with G2 and G3 were provided with an even filling of metal flow. Comparing the components with farthest and nearest gate, there was non-uniform filling. 
The result obtained from SSPC runner set-up was almost equal to the CSSC. The first two and next two casting provided an even filling in a sequential manner, but components with G1 and G2 as well as G3 and G4 castings exhibited an uneven filling in a sequential pattern. The runner set-up in CSPC provided a better filling sequence. It was observed that when a runner was located towards centre, air gaps occurred on both sides and resulted to casting defects against the quality of the components. Evidently, the CS-RE-PC runner provided an excellent filling parameter and sequence.

Based on simulation results, runner system was mainly responsible for an uneven filling sequence and minimum yields percentage. Consequently, runner was modified by locating it away from the main runner for CS-RE-PC mould design, as shown in Fig. 8, which later provided the best filling parameters when compared with other four runners.

Fig. 8. Five different 3D mould flow simulation results.

\section{Experimental: Inspection methods}

\subsection{Macroscopic inspection}

It was apparent to notice that both SSSC and CSSC mould set-ups were affected by the defects. Minor shrinkage, pinholes and porosity defects might have occurred due to the dissolution of gases in the SSPC design. Moreover, uneven structure shrinkage defects and uniform blow holes were observed in CSPC set-up. Comparatively, CS-RE-PC mould set-up exhibited a nearly defect-free surface with a naked eye scanning, as depicted in Fig. 9.

Fig. 9. Cut-section views of the casting components.

\subsection{Optical microscopic examination}


Each component was cut into two halves and the casting defects were examined with a Motic optical microscope, which was digitally controlled by Plus 2.0 ML image processing software. Fig. 10 depicts that the SSSC mould set-up showed an irregular structure on top of the casting, due to the uneven metal filling, outside slight up and downs. Furthermore, a spherical or elongated cavity defect was observed in CSSC mould design, as shown in Fig. 10. And also, the SSPC and CSPC mould set-up components produced the biggest shrinkage defects and uneven areas, respectively. On the other hand, the CS-RE-PC set-up comparatively exhibited minimum defects on both outer and inner surfaces, as shown in Fig. 11.

Fig. 10. Serial connection cut-section views (left) and optical microscopic images(right) of (a) SSSC and (b) CSSC casting results.

Fig. 11. Parallel connection cut-section views (left) and optical microscopic images(right) of (a) SSPC, (b) CSPC and (c) CS-RE-PC casting results.

\subsection{Ultrasonic inspection}

Smoothened $2 \mathrm{~mm}$ thick samples were subjected to non-destructive testing thrice in each case to ensure the repeatability, reliability and accuracy. Around 60 components were ultrasonically tested, From the results obtained, $80 \%$ of SSSC components possessed defects, with a rejection ratio of 7 out of 10 . Up to $70 \%$ of CSSC moulds have porosity defects, followed by $60 \%$ defects in the CSPC components. The results of SSPC mould set-up was comparatively better, with 50\% defects. But, the CS-RE-PC components exhibited superior or best results with only $20 \%$ acceptable defect zone, when compared with other four set-ups.

\subsection{X-ray examination}


Five set-ups of mould were prepared in five trails, each trail contained four components. Around 20 components were received from each set-up to produce a total of 100 (5 x 20) components. All components based on the variation of velocity and discharges were examined on screen of the X-ray machine, and the results obtained are depicted in Fig. 12. The qualities of first (C1) and second (C2) SSPC components were similar to the third (C3) and fourth (C4) components of SSSC.

Fig. 12. X-ray micrographs of casting defects of the five mould set-ups/designs.

The C2 and C3 components of CSSC set-up produced more porosity and pin hole defects when compared with CSPC. However, the CSPC has greater severe defects when compared with other three aforementioned set-ups: SSPC, SSSC and CSSC. The defect obtained during simulation process showed the same casting flaws, as confirmed from the X-ray test results obtained. Most importantly, the CS-RE-PC mould component exhibited the optimum or best quality, based on the X-ray test results obtained and when compared with its counterparts.

\section{Conclusions}

Casting quality of various multi-gate system in sand casting process has been investigated, using both experimental and simulation methods. The molten liquid used were aluminium alloy (LM4(Al-Si5Cu3)) and water, under same parameters and conditions. Based on both experimental and simulation results obtained, the following concluding remarks were subsequently drawn:

- Considering the serially connected multi-gate system, the SSSC mould set-up with G1 to G4 components produced uneven gate velocities and the fillings attained a low quality. Besides, 
CSSC design showed that components with G1 and G4 were approximately equal (G1 = G4) and components with $\mathrm{G} 2$ and G3 were nearly the same $(\mathrm{G} 2=\mathrm{G} 3)$. These results implied two different filling sequences and hence, the gate velocities also produced two different component qualities.

- From the parallel connected multi-gate system, the SSPC mould set-up recorded similar results, but with different pair components: components with G1 and G2 were nearly equal $(\mathrm{G} 1=\mathrm{G} 2)$ and components with G3 and G4 were approximately equal (G3=G4). CSPC has a comparatively equal gate velocities and component fillings, but its simulation results showed a few varied casting defects. The CS-RE-PC mould design exhibited a comparatively best or optimum component filling and equal gate velocity results.

- Importantly, it was evident that the CS-RE-PC mould set-up was most suitable multi-gate system in sand casting process, with optimum runner system for four-cavity application. Its runner design produced comparatively best flow rate and consequently least defective casting component, as confirmed or observed from visual, optical microscopic, ultrasonic and X-ray examinations.

- Based on the simulation results obtained, it was observed that runner system was mainly responsible for an uneven filling sequence and minimum yield percentage. Hence, runner was modified by re-locating it away from the main runner for the optimum CS-RE-PC design.

- Applicably, the manufacturing/casting industries have a lot to benefit from this innovative investigation, supported agreeably by both experimental and simulation approaches. It has direct application mostly in multi-gate system with four-cavity component or runner system, where low-cost sand casting defects are almost inevitable.

\section{Acknowledgement}


The authors thank the Department of Mechanical Engineering, Kalasalingam Academy of Research and Education, Krishnankoil 626126, India. Also, the authors sincerely appreciate all the technical supports received from the Sri Metals Works Sand Company, Coimbatore, India, where the experimental works of this study were conducted.

\section{Reference}

[1] Ingle PD, Narkhede BE. A literature survey of methods to study and analyze the gating system design for its effect on casting quality. Mater Today Proc 2018;5(2): 5421-9.

[2] Hsu FY, Jolly MR, Campbell JA. A multiple-gate runner system for gravity casting. J $\begin{array}{lll}\text { Mater Proc 2009;209(17):5736-50. } & \text { Technol }\end{array}$ https://doi.org/10.1016/j.jmatprotec.2009.06.003.

[3] Renukananda KH, Ravi B. Multi-gate systems in casting process: Comparative study of liquid metal and water flow. Mater Manuf Proc 2016;31(8):1091-101. https://doi.org/10.1080/10426914.2015.1037911.

[4] Rajkumar I, Rajini N. Effectiveness of feeding system for enhanced product quality in sand casting industries. Int J Rec Technol Eng 2019;8:231-7. https://doi.org/10.35940/ijrte.D1048.1284S219.

[5] Masoumi M, Hu H, Hedjazi J, Boutorabi M. Effect of gating design on mold filling. Trans Amer Foundry Soc 2005;113:185-96.

[6] Shaikh MBN, Ahmad S, Khan A, Ali M. Optimization of multi-gate systems in casting process: Experimental and simulation studies. In IOP Conf Ser Mater Sci Eng 2018;404:110. https://doi.org/10.1088/1757-899X/404/1/012040.

[7] Renukananda KH, Chavan A, Ravi B. Flow rates in multi-gate systems: Experimental and simulation studies. Ind Foundry J 2012; 58(4):23-7. 
[8] Halappa RK, Chheda U, Bhallamudi R. Flow through multi-gate gating system: experimental and simulation studies. In Proceedings of ASME International Mechanical Engineering Congress and Exposition, 2013, Nov. 15. American Society of Mechanical Engineers Digital Collection. 15-21. https://doi.org/10.1115/IMECE2013-64732.

[9] Rajkumar I, Rajini N, Jeeva M, Arunkumar K, Jeeva M, Kaliraj P. Observation of flow and discharge through multi-gating system. Int $\mathbf{J}$ Eng Adv Technol 2019;9:836-9. https://doi.org/10.35940/ijeat.A1052.1291S419.

[10] Sama SR, Badamo T, Lynch P, Manogharan G. Novel sprue designs in metal casting via $3 \mathrm{D}$ sand-printing.

Add

Manuf 2019;25:563-78. https://doi.org/10.1016/j.addma.2018.12.009.

[11] Seo HY, Seo PK, Kang CG. A study on the S/W application for a riser design process for fabricating axisymmetric large offshore structures by using a sand casting process. Int $\mathbf{J}$ Naval Arch Ocean Eng 2019;11(1):462-73. https://doi.org/10.1016/j.jnaoe.2018.08.003.

[12] Iqbal H, Sheikh AK, Al-Yousef A, Younas M. Mold design optimization for sand casting of complex geometries using advance simulation tools. Mat Manuf Proc 2012;27(7):77585. https://doi.org/10.1080/10426914.2011.648250.

[13] Fu Y, Wang H, Zhang C, Hao H. Numerical simulation and experimental investigation of a thin-wall magnesium alloy casting based on a rapid prototyping core making method. Int $\mathrm{J}$ Cast Metals Res 2018;31(1):37-46. https://doi.org/10.1080/13640461.2017.1365477.

[14] Kermanpur A, Mahmoudi S, Hajipour A. Numerical simulation of metal flow and solidification in the multi-cavity casting moulds of automotive components. J Mater Proc Technol 2008;206(1-3):62-68. https://doi.org/10.1016/j.jmatprotec.2007.12.004. 
[15] Nimbulkar SL, Dalu RS. Design optimization of gating and feeding system through simulation technique for sand casting of wear plate. Persp Sci 2016;8:39-42. https://doi.org/10.1016/j.pisc.2016.03.001.

[16] Papanikolaou M, Pagone E, Salonitis K, Jolly M. Sustainability-based evaluation of casting gating systems: a multi-criteria decision-making approach. Procedia Manuf 2020;43:704-11.

[17] Ingle PD, Narkhede BE. A literature survey of methods to study and analyze the gating system design for its effect on casting quality. Mater Today Proc 2018;5:5421-9.

[18] Zheng J, Chen A, Zheng W, Zhou X, Bai B, Wu J, Ling W, Ma H, Wang W. Effectiveness analysis of resources consumption, environmental impact and production efficiency in traditional manufacturing using new technologies: Case from sand casting. Energy Convers Manag 2020;209:112671.

[19] Zheng J, Zhou X, Yu Y, Wu J, Ling W, Ma H. Low carbon, high efficiency and sustainable production of traditional manufacturing methods through process design strategy: Improvement process for sand casting defects. J Clean Prod 2020;253:119917.

[20] Barot RP, Ayar VS. Casting simulation and defect identification of geometry varied plates with experimental validation. Mater Today Proc 2020;26(2):2754-62.

[21] Borikar GP, Chavan ST. Optimization of casting yield in multi-cavity sand moulds of alalloy components. Mater Today Proc 2020;28(2):819-24.

[22] Mehta N, Gohil AV, Dave KG, Patel VB. Development of casting defect analysis module through integrated approach for small and medium scale industries. Mater Today Proc 2020;1-8. https://doi.org/10.1016/j.matpr.2020.09.244. 
[23] Kermanpur A, Mahmoudi S, Hajipour A. Numerical simulation of metal flow and solidification in the multi-cavity casting moulds of automotive components. J Mater Proc Technol 2008;206(1-3):62-8.

\section{Table 1}

Parameters of aluminium alloy and water materials used.

\begin{tabular}{clccc}
\hline S/No & Parameter & Unit & Water & Aluminium alloy (LM4) \\
\hline 1. & Pressure head & $\mathrm{m}$ & 0.37 & 0.37 \\
2. & Velocity & $\mathrm{m} / \mathrm{s}$ & 2.69 & 2.69 \\
3. & Characteristic length & $\mathrm{mm}$ & 12 & 12 \\
4. & Pouring Temperature & ${ }^{\circ} \mathrm{C}$ & 30 & 650 \\
5. & Density & $\mathrm{kg} / \mathrm{m}^{3}$ & 995.6 & 2362 \\
6. & Dynamic viscosity & Centipoises & 1 & 3 \\
7. & Kinematic viscosity & Centistokes & 1 & 1.27 \\
\hline
\end{tabular}

Table 2

The flow input parameters.

\begin{tabular}{cll}
\hline S/No & Parameters & Data \\
\hline 1. & Geometric model type & stl file \\
2. & Material & LM4(A1-Si5Cu3) \\
3. & Mould temperature & $140{ }^{\circ} \mathrm{C}$ \\
4. & Molten metal temperature $(\mathrm{LM} 4(\mathrm{Al}-\mathrm{Si} 5 \mathrm{Cu} 3))$ & $720^{\circ} \mathrm{C}$, \\
5. & Poring type & Side poring \\
6. & Component weight & $343.75 \mathrm{~g}$ \\
7. & Component size & $5 \times 5 \times 5 \mathrm{~cm}$ \\
8. & Mesh cell size & $1 \mathrm{~mm} \times 1 \mathrm{~mm}$ \\
\hline
\end{tabular}




\section{Table 3}

Existing mould design for metal flow rate of aluminium alloy.

\begin{tabular}{ccccccccc}
\hline & \multicolumn{3}{c}{ SSSC } & \multicolumn{5}{c}{ CSSC } \\
\cline { 2 - 9 } Gate & $\begin{array}{c}\text { Avg. Vol. } \\
\left(\mathrm{cm}^{3}\right)\end{array}$ & T $(\mathrm{s})$ & $\begin{array}{c}\text { Vol. flow } \\
\text { rate } \\
\left(\mathrm{cm}^{3} / \mathrm{s}\right)\end{array}$ & $(\%)$ & $\begin{array}{c}\text { Avg. Vol. } \\
\left(\mathrm{cm}^{3}\right)\end{array}$ & $\mathrm{T}(\mathrm{s})$ & $\begin{array}{c}\text { Vol. flow } \\
\text { rate } \\
\left(\mathrm{cm}^{3} / \mathrm{s}\right)\end{array}$ & $(\%)$ \\
\hline G1 & 58 & 4 & 14.50 & 16.20 & 118 & 5 & 23.60 & 32.33 \\
G2 & 83 & 4 & 20.75 & 23.18 & 62 & 5 & 12.40 & 16.99 \\
G3 & 95 & 4 & 23.75 & 26.54 & 65 & 5 & 13.00 & 17.81 \\
G4 & 122 & 4 & 30.50 & 34.08 & 120 & 5 & 24.00 & 32.88 \\
Total & 358 & & 89.50 & 100.00 & 365 & & 73.00 & 100.00 \\
\hline
\end{tabular}

\section{Table 4}

Water flow rate of modified runner design.

\begin{tabular}{|c|c|c|c|c|c|c|c|c|c|c|c|c|}
\hline \multirow[b]{2}{*}{$\begin{array}{l}\text { Gate } \\
\text { No. }\end{array}$} & \multicolumn{4}{|c|}{ SSPC } & \multicolumn{3}{|c|}{ CSPC } & \multicolumn{5}{|c|}{ CS-RE-PC } \\
\hline & $\begin{array}{l}\text { Avg. } \\
\text { vol. } \\
\text { (cm3) }\end{array}$ & $\begin{array}{c}\mathrm{T} \\
\text { (s) }\end{array}$ & $\begin{array}{l}\text { Vol. } \\
\text { flow } \\
\text { rate } \\
(\mathrm{cm} 3 / \mathrm{s})\end{array}$ & $(\%)$ & $\begin{array}{l}\text { Avg. } \\
\text { vol. } \\
(\mathrm{cm} 3)\end{array}$ & $\begin{array}{c}\mathrm{T} \\
\text { (s) }\end{array}$ & $\begin{array}{l}\text { Vol. } \\
\text { flow } \\
\text { rate } \\
(\mathrm{cm} 3 / \mathrm{s})\end{array}$ & $(\%)$ & $\begin{array}{l}\text { Avg. } \\
\text { Vol. } \\
(\mathrm{cm} 3)\end{array}$ & $\begin{array}{l}\mathrm{T} \\
\text { (s) }\end{array}$ & $\begin{array}{l}\text { Vol. } \\
\text { flow } \\
\text { rate } \\
(\mathrm{cm} 3 / \mathrm{s})\end{array}$ & $(\%)$ \\
\hline G1 & 65 & 3 & 21.67 & 17.20 & 118 & 3 & 39.33 & 24.69 & 123 & 3 & 41.00 & 25.10 \\
\hline G2 & 66 & 3 & 22.00 & 17.46 & 119 & 3 & 39.67 & 24.90 & 122 & 3 & 40.67 & 24.90 \\
\hline G3 & 123 & 3 & 41.00 & 32.54 & 120 & 3 & 40.00 & 25.11 & 123 & 3 & 41.00 & 25.10 \\
\hline G4 & 124 & 3 & 41.33 & 32.80 & 121 & 3 & 40.33 & 25.31 & 122 & 3 & 40.67 & 24.90 \\
\hline Total & 378 & & 126.00 & 100 & 478 & & 159.33 & 100.00 & 490 & & 163.33 & 100.00 \\
\hline
\end{tabular}


Table 5

Existing and Modified runner design for the metal flow rate.

\begin{tabular}{|c|c|c|c|c|c|c|c|c|c|c|c|c|c|c|c|c|c|}
\hline \multirow[b]{2}{*}{ Gate } & \multicolumn{4}{|c|}{ SSSC } & \multicolumn{4}{|c|}{ CSSC } & \multicolumn{4}{|c|}{ SSPC } & \multicolumn{4}{|c|}{ CSPC } & \multirow[b]{2}{*}{$\begin{array}{l}\text { Avg. } \\
\text { vol. } \\
\left(\mathrm{cm}^{3}\right)\end{array}$} \\
\hline & $\begin{array}{l}\text { Avg. } \\
\text { vol. } \\
\left(\mathrm{cm}^{3}\right)\end{array}$ & & $\begin{array}{l}\text { Vol. } \\
\text { flow } \\
\text { rate } \\
\left(\mathrm{cm}^{3} / \mathrm{s}\right)\end{array}$ & $(\%)$ & $\begin{array}{l}\text { Avg. } \\
\text { vol. } \\
\left(\mathrm{cm}^{3}\right)\end{array}$ & $\begin{array}{l}\mathrm{T} \\
(\mathrm{s})\end{array}$ & $\begin{array}{l}\text { Vol. } \\
\text { flow } \\
\text { rate } \\
\left(\mathrm{cm}^{3} / \mathrm{s}\right)\end{array}$ & $(\%)$ & $\begin{array}{l}\text { Avg. } \\
\text { vol. } \\
\left(\mathrm{cm}^{3}\right)\end{array}$ & $\begin{array}{l}\mathrm{T} \\
\text { (s) }\end{array}$ & $\begin{array}{l}\text { Vol. } \\
\text { flow } \\
\text { rate } \\
\left(\mathrm{cm}^{3} / \mathrm{s}\right)\end{array}$ & $(\%)$ & $\begin{array}{c}\text { Avg. } \\
\text { vol. } \\
\left(\mathrm{cm}^{3}\right)\end{array}$ & $\begin{array}{l}\mathrm{T} \\
(\mathrm{s})\end{array}$ & $\begin{array}{l}\text { Vol. } \\
\text { flow } \\
\text { rate } \\
\left(\mathrm{cm}^{3} / \mathrm{s}\right)\end{array}$ & $(\%)$ & \\
\hline G1 & 58 & 4 & 14.50 & 16.20 & 118 & 5 & 23.60 & 32.33 & 61 & 4 & 15.25 & 16.80 & 118 & 5.5 & 21.45 & 25.00 & 122 \\
\hline G2 & 83 & 4 & 20.75 & 23.18 & 62 & 5 & 12.40 & 16.99 & 63 & 4 & 15.75 & 17.36 & 117 & 5.5 & 21.27 & 24.79 & 121 \\
\hline G3 & 95 & 4 & 23.75 & 26.54 & 65 & 5 & 13.00 & 17.81 & 119 & 4 & 29.75 & 32.78 & 119 & 5.5 & 21.64 & 25.21 & 121 \\
\hline G4 & 122 & 4 & 30.50 & 34.08 & 120 & 5 & 24.00 & 32.88 & 120 & 4 & 30.00 & 33.06 & 118 & 5.5 & 21.45 & 25.00 & 120 \\
\hline Total & 358 & & 89.50 & 100.00 & 365 & & 73.00 & 100.00 & 363 & & 90.75 & 100.00 & 472 & & 85.82 & 100.00 & 484 \\
\hline
\end{tabular}

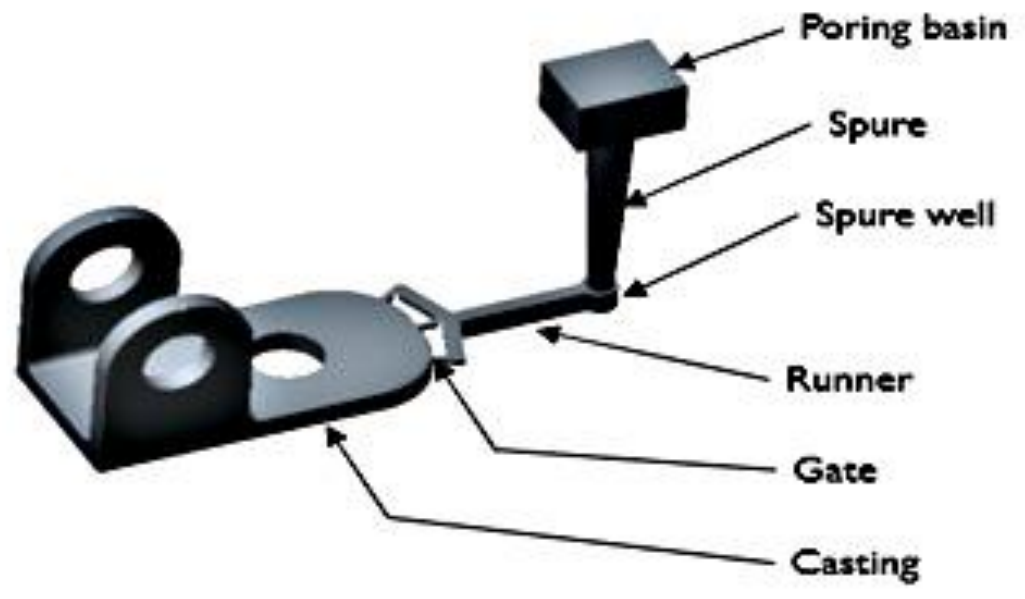

Fig. 1. Basic components of a classic gating structure. 

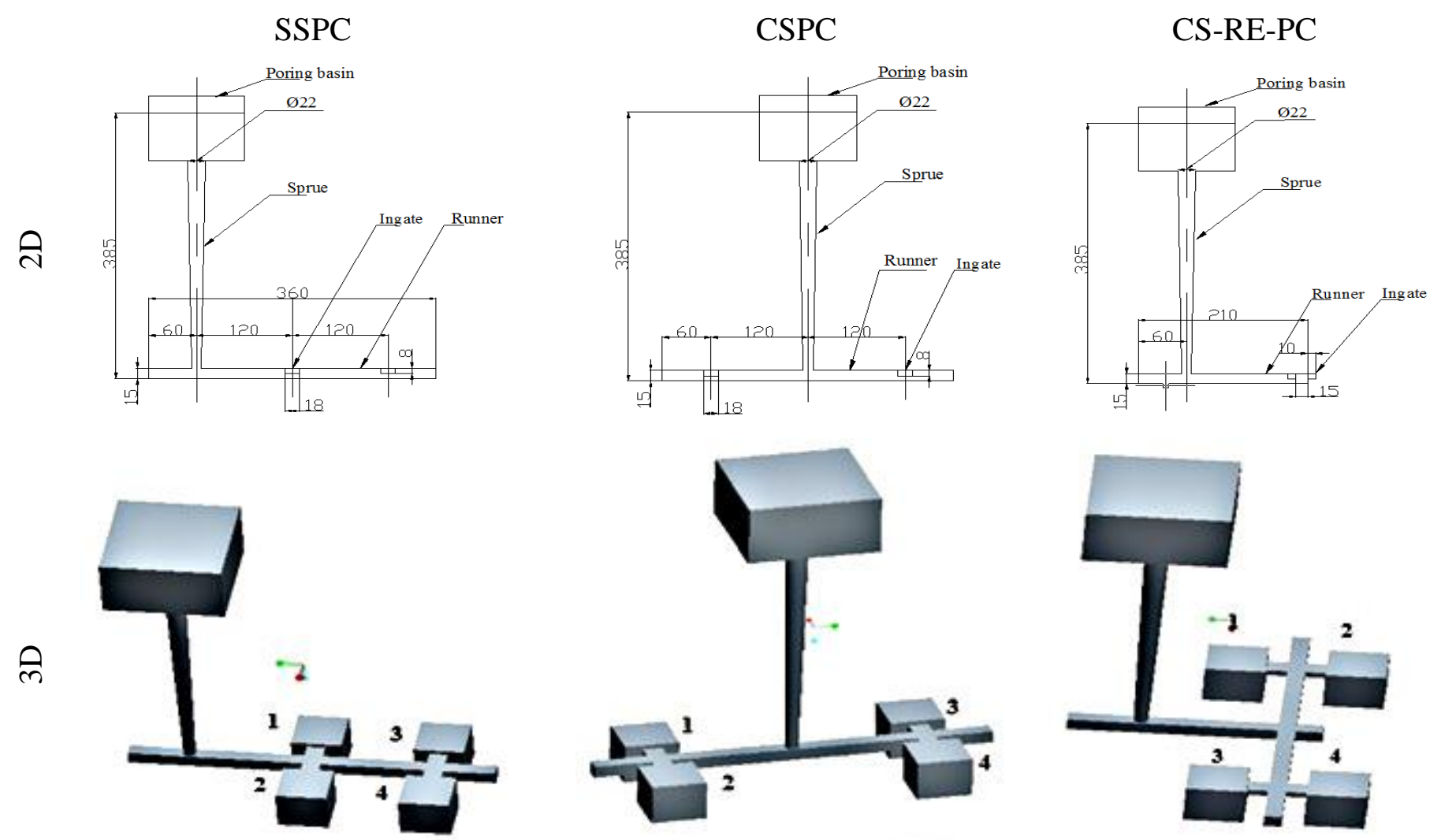

Fig. 2. Development of 2D and 3D casting models for different MGDs using AutoCAD and Creo 3.0 software.

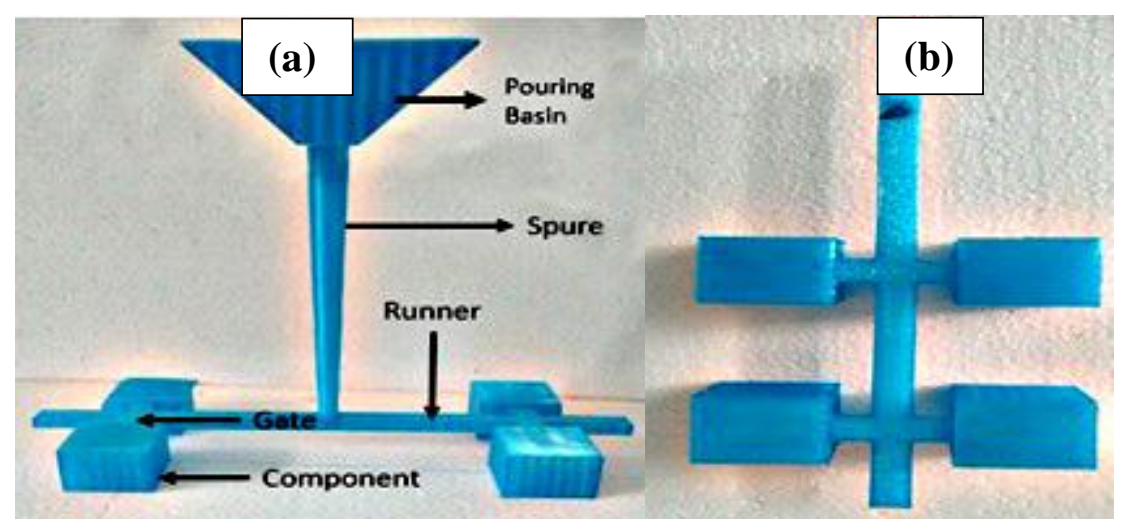

Fig. 3. (a) CSPC and (b) SSPC plastic patterns developed by 3D printing. 

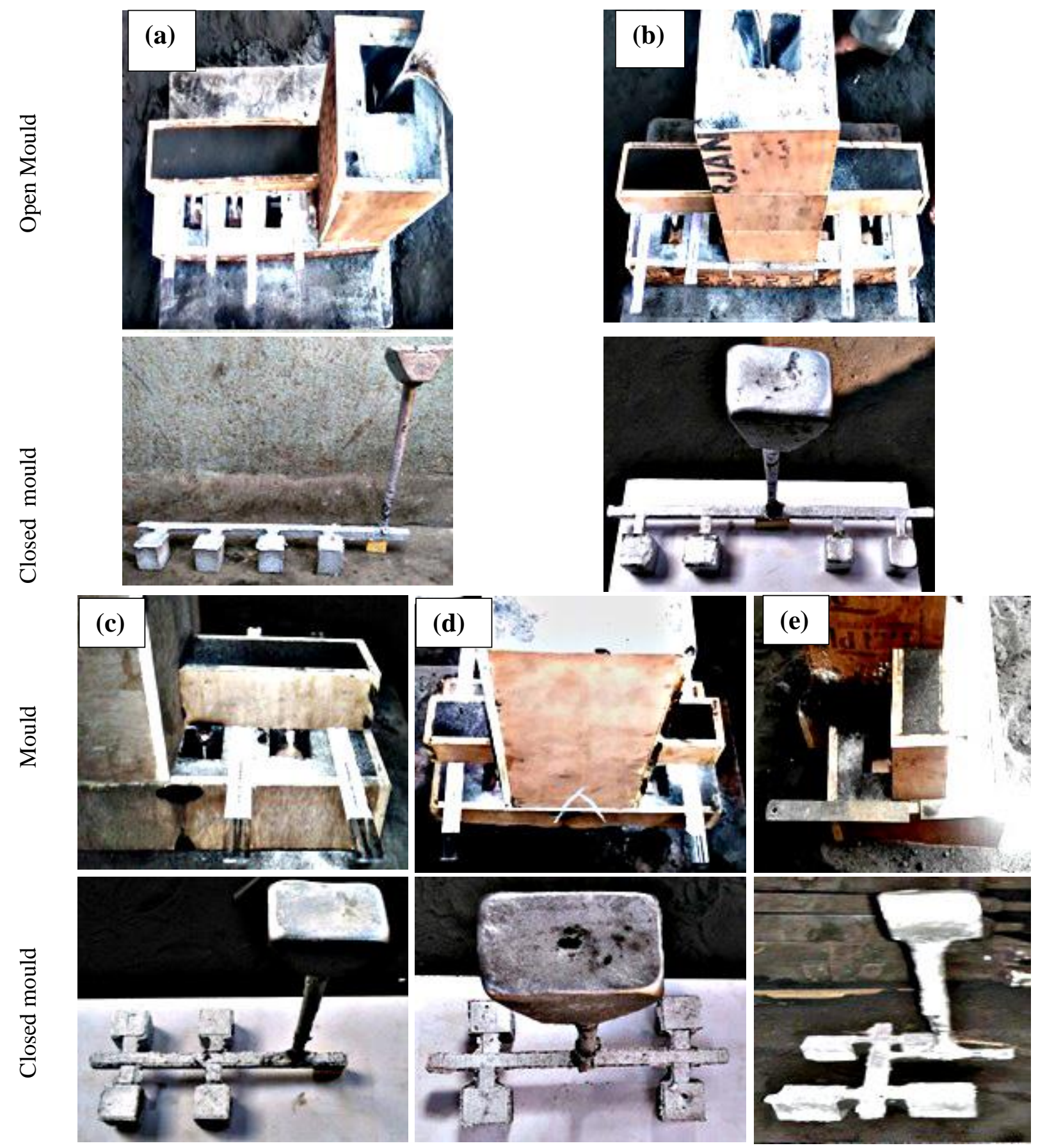

Fig. 4. Experimental setup of sand casting process with open and closed mould for different MGDs: (a) SSSC, (b) CSSC, (c) SSPC, (d) CSPC and (e) CS-RE-PC. 

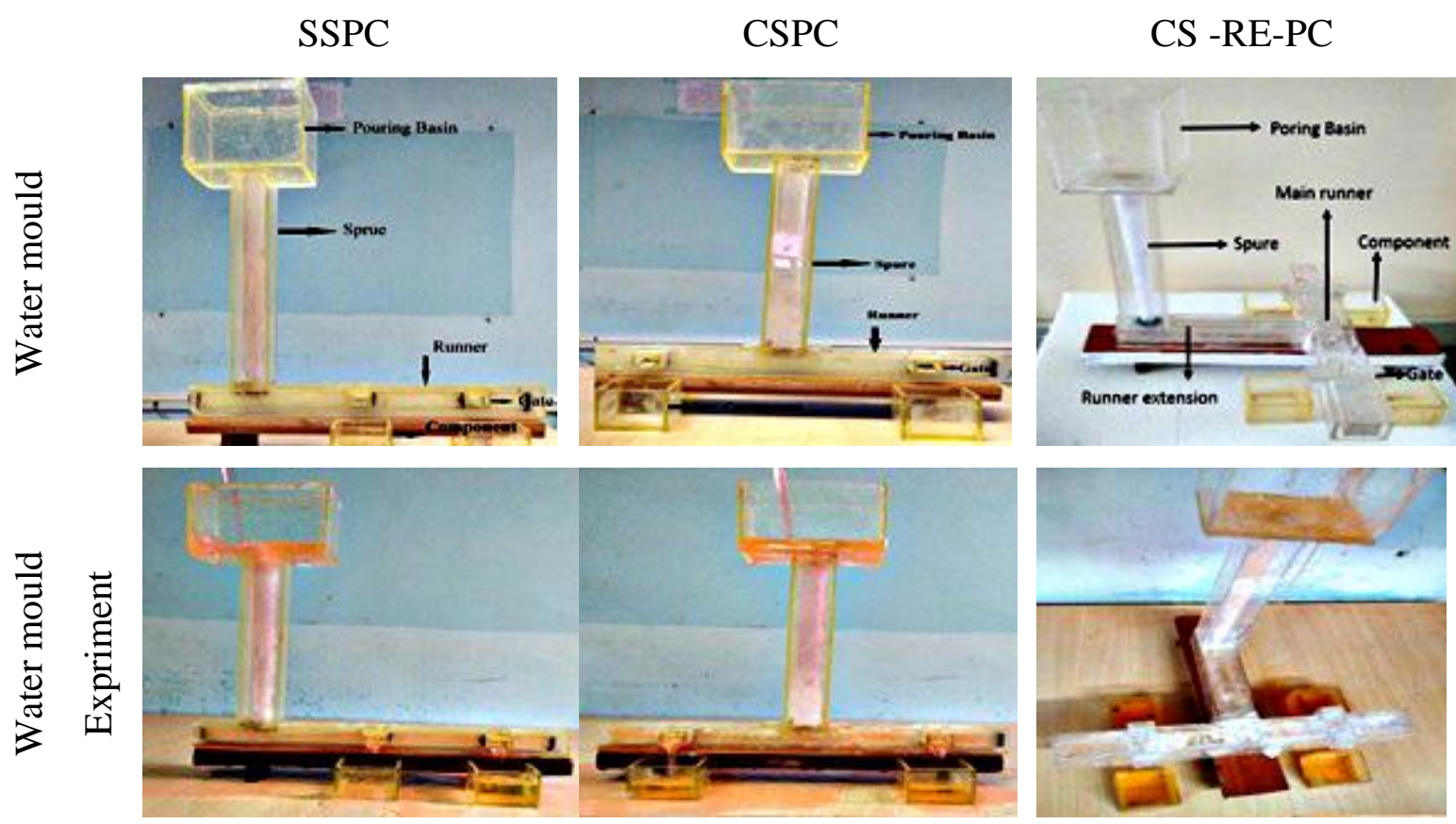

Fig. 5. Water mould experiment set-ups for various MGDs.
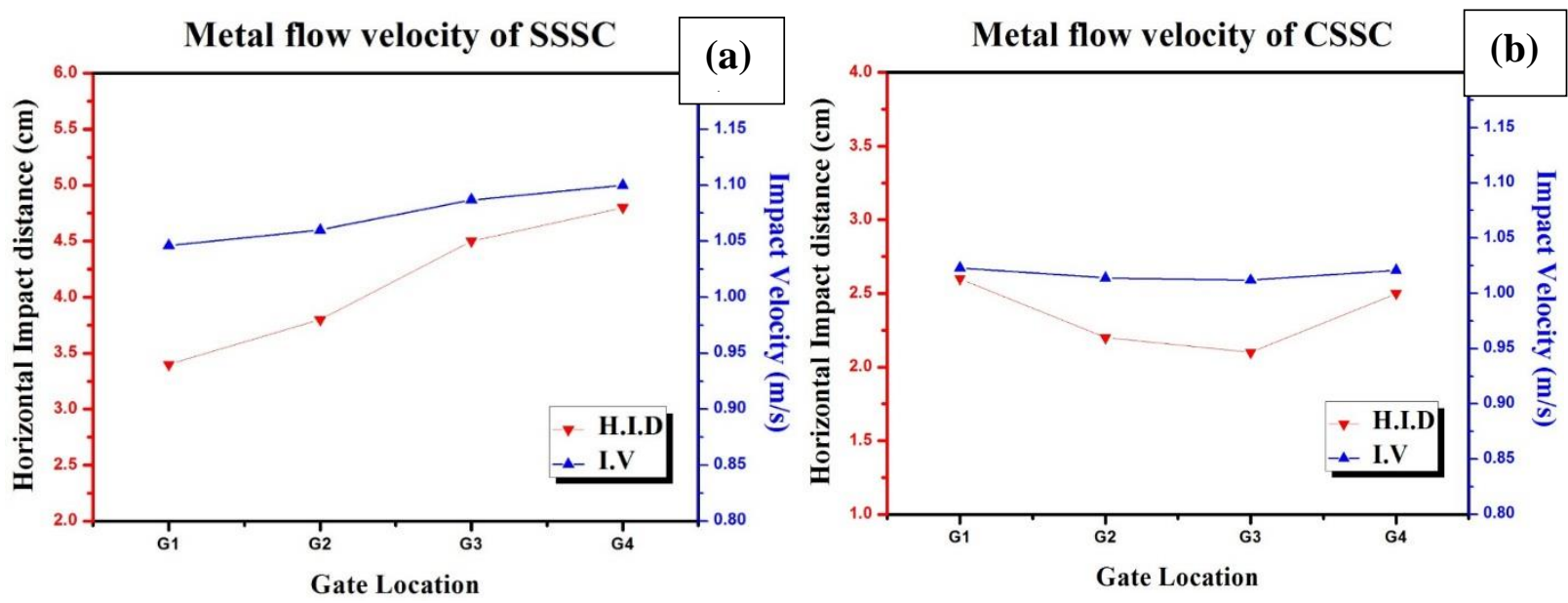

Fig. 6. Metal flow velocities of (a) SSSC and (b) CSSC. 

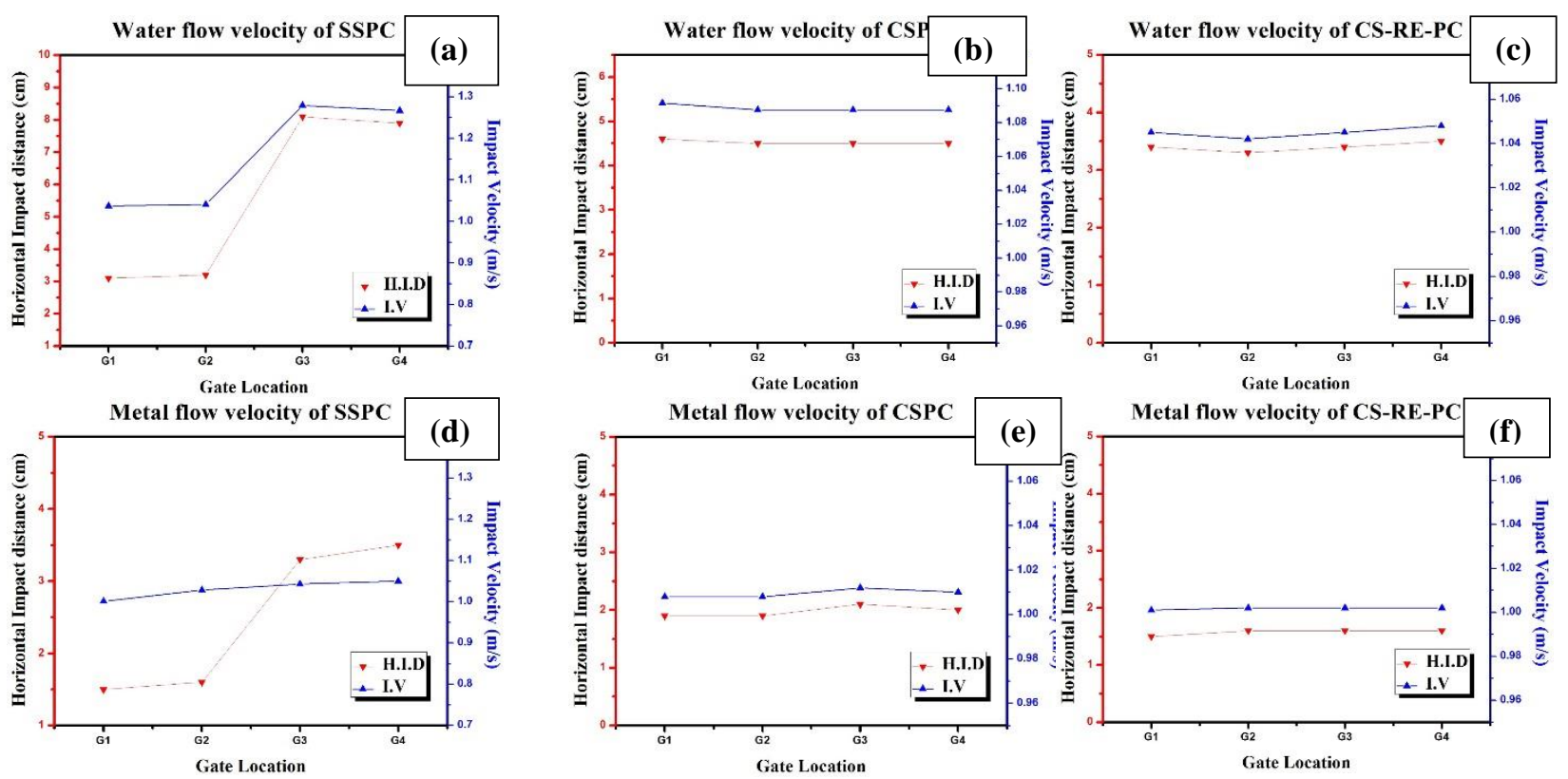

Fig. 7. Water flow velocities of (a) SSPC, (b) CSPC and (c) CS-RE-PC as well as metal flow velocities of (d) SSPC, (e) CSPC and (f) CS-RE-PC.

$\frac{0}{\frac{0}{3}}$

SSSC

CSSC
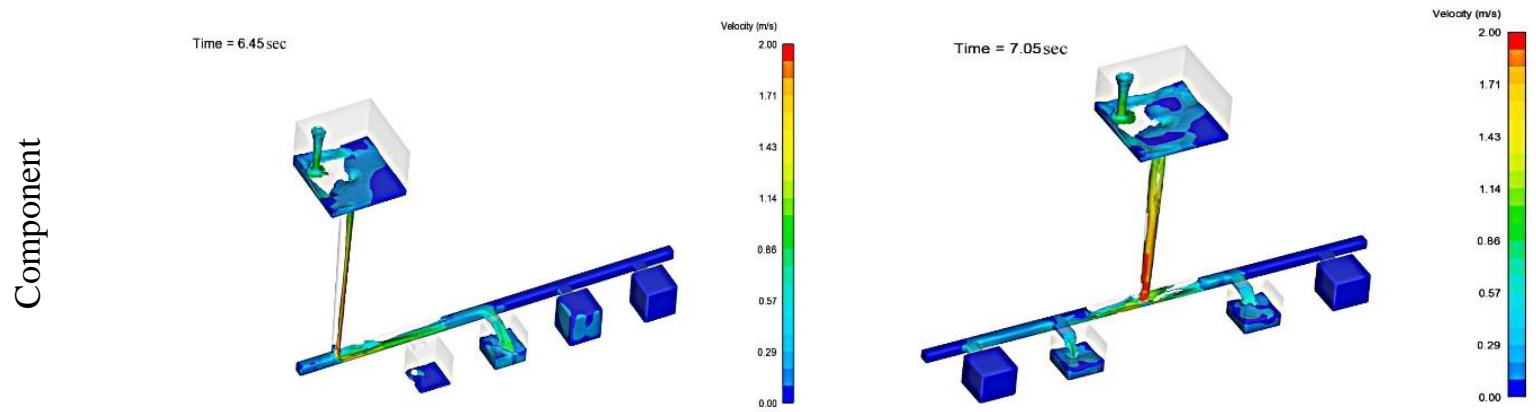

$\frac{0}{3}$

SSPC

CSPC

CS-RE-PC
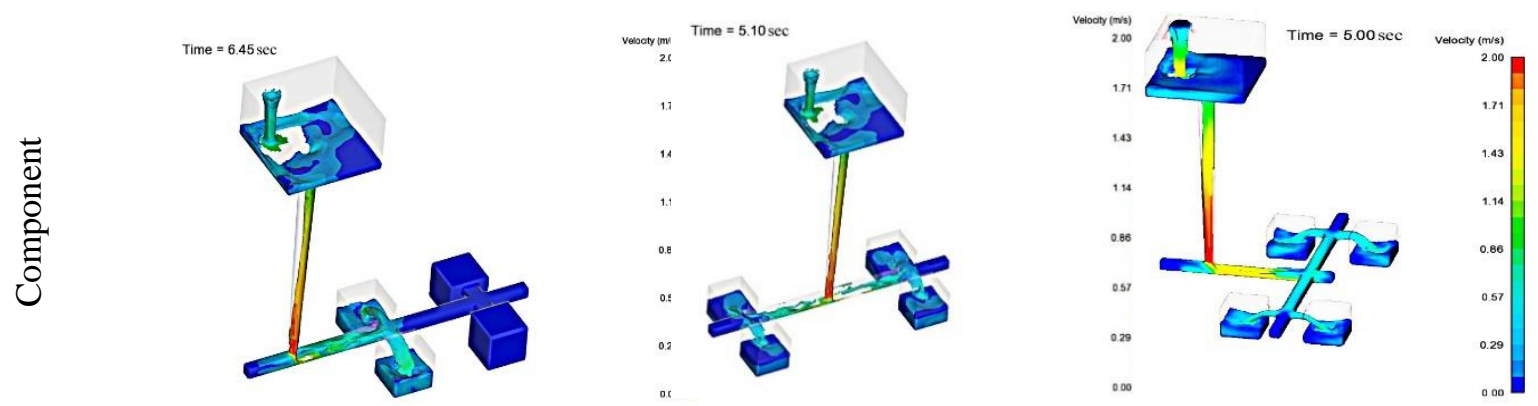

Fig. 8. Five different 3D mould flow simulation results. 
$\frac{7}{\overline{0}}$

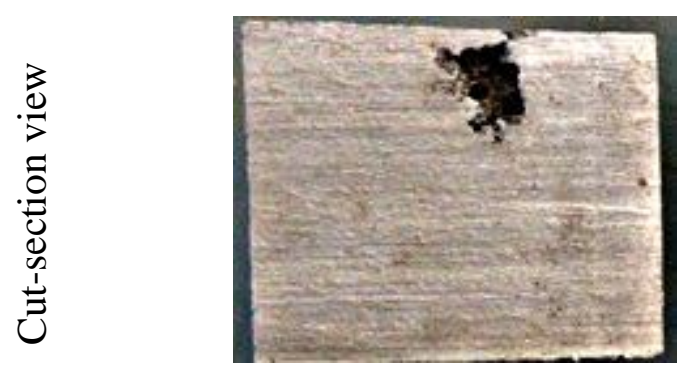

$\frac{0}{3}$

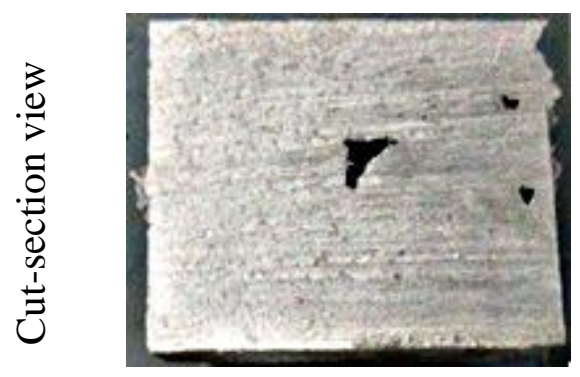

CSSC

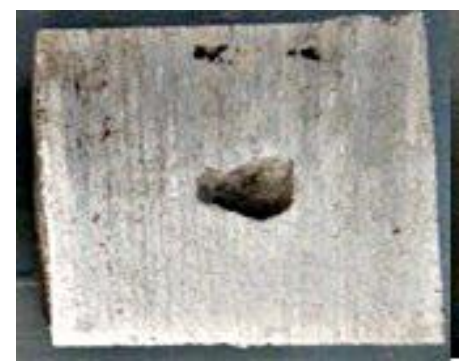

CSPC

CS-RE-PC

Fig. 9. Cut-section views of the casting components. 


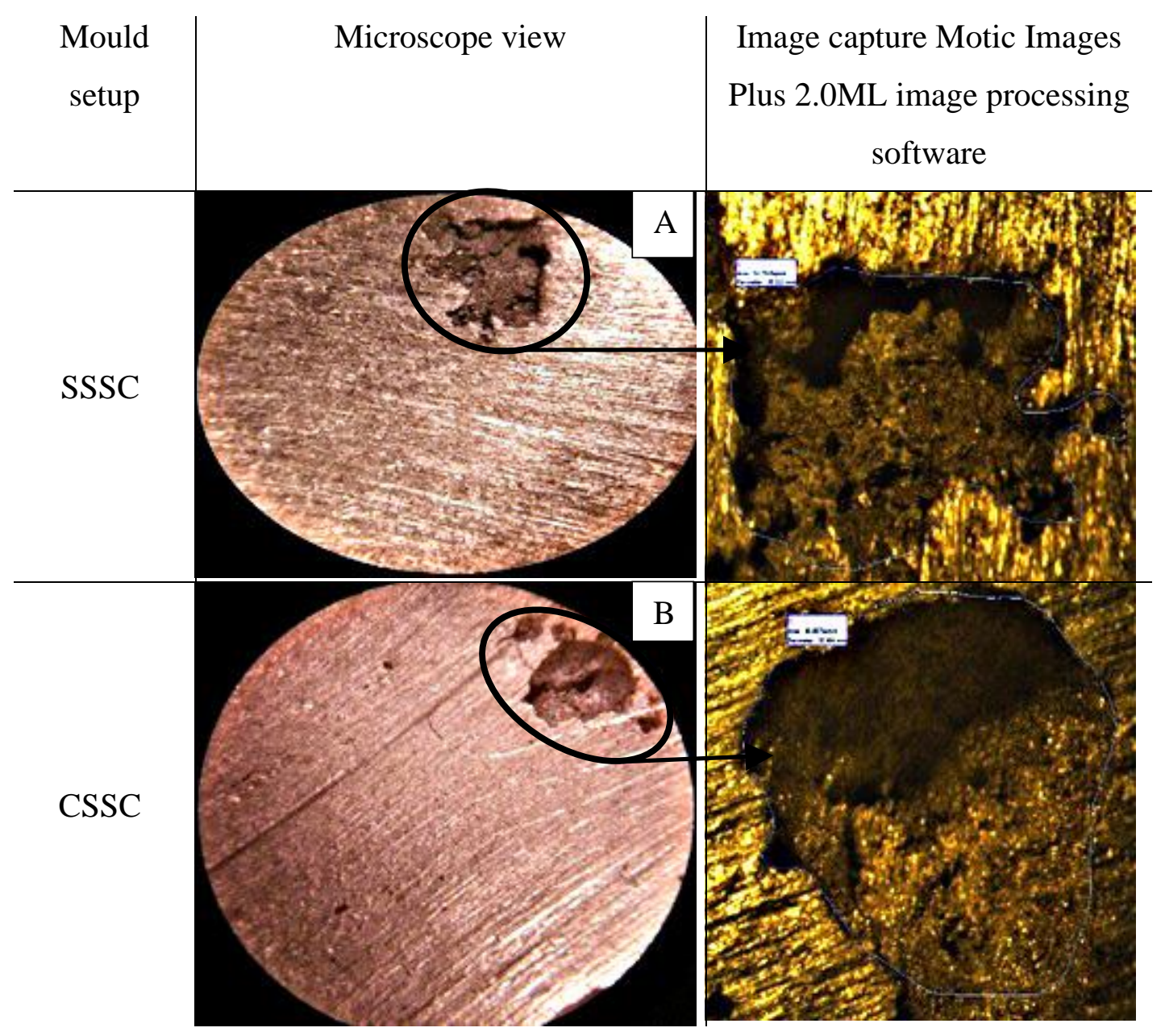

Fig. 10. Serial connection cut-section views (left) and optical microscopic images (right) of (a) SSSC and (b) CSSC casting results. 


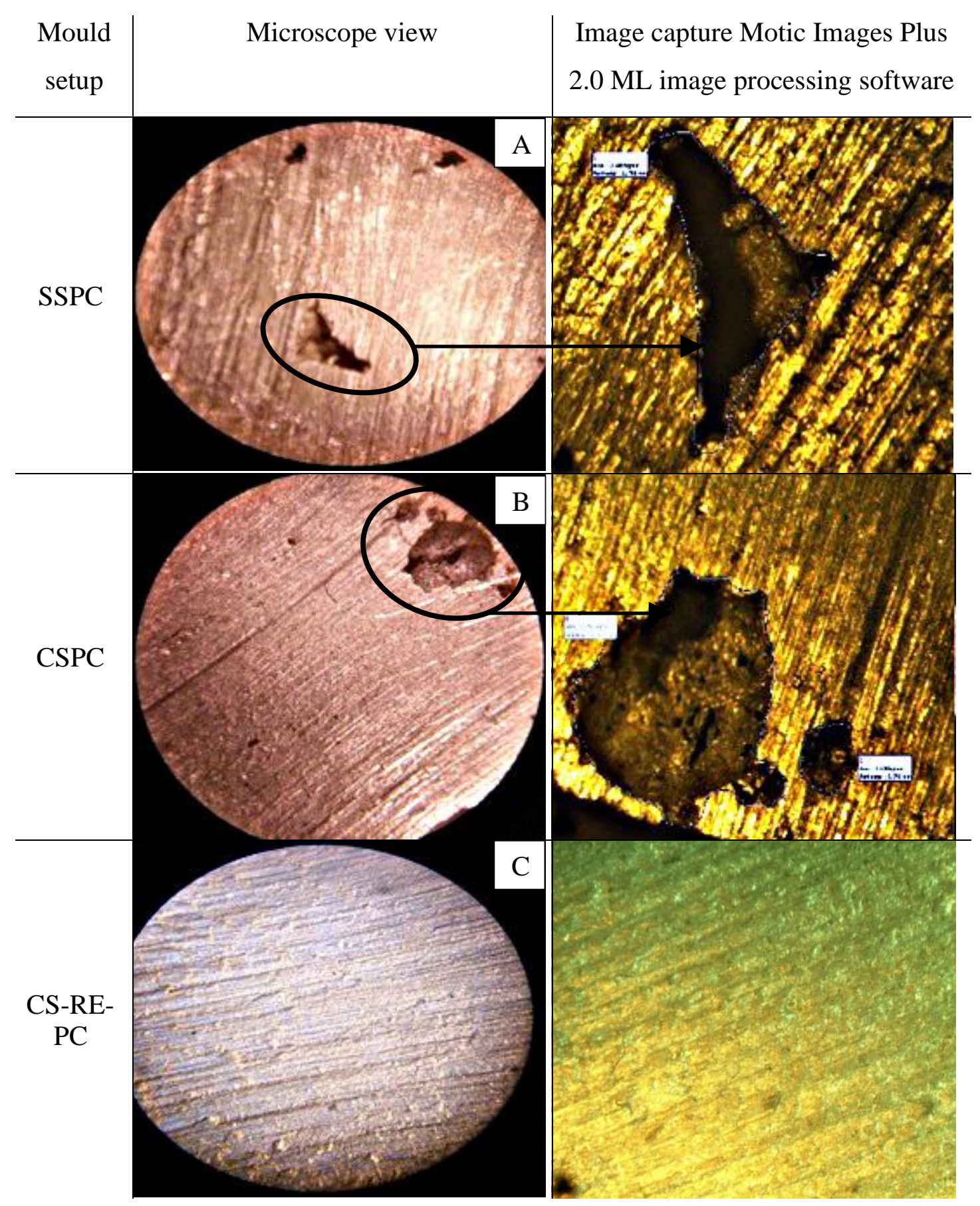

Fig. 11. Parallel connection cut-section views (left) and optical microscopic images (right) of (a) SSPC, (b) CSPC and (c) CS-RE-PC casting results. 


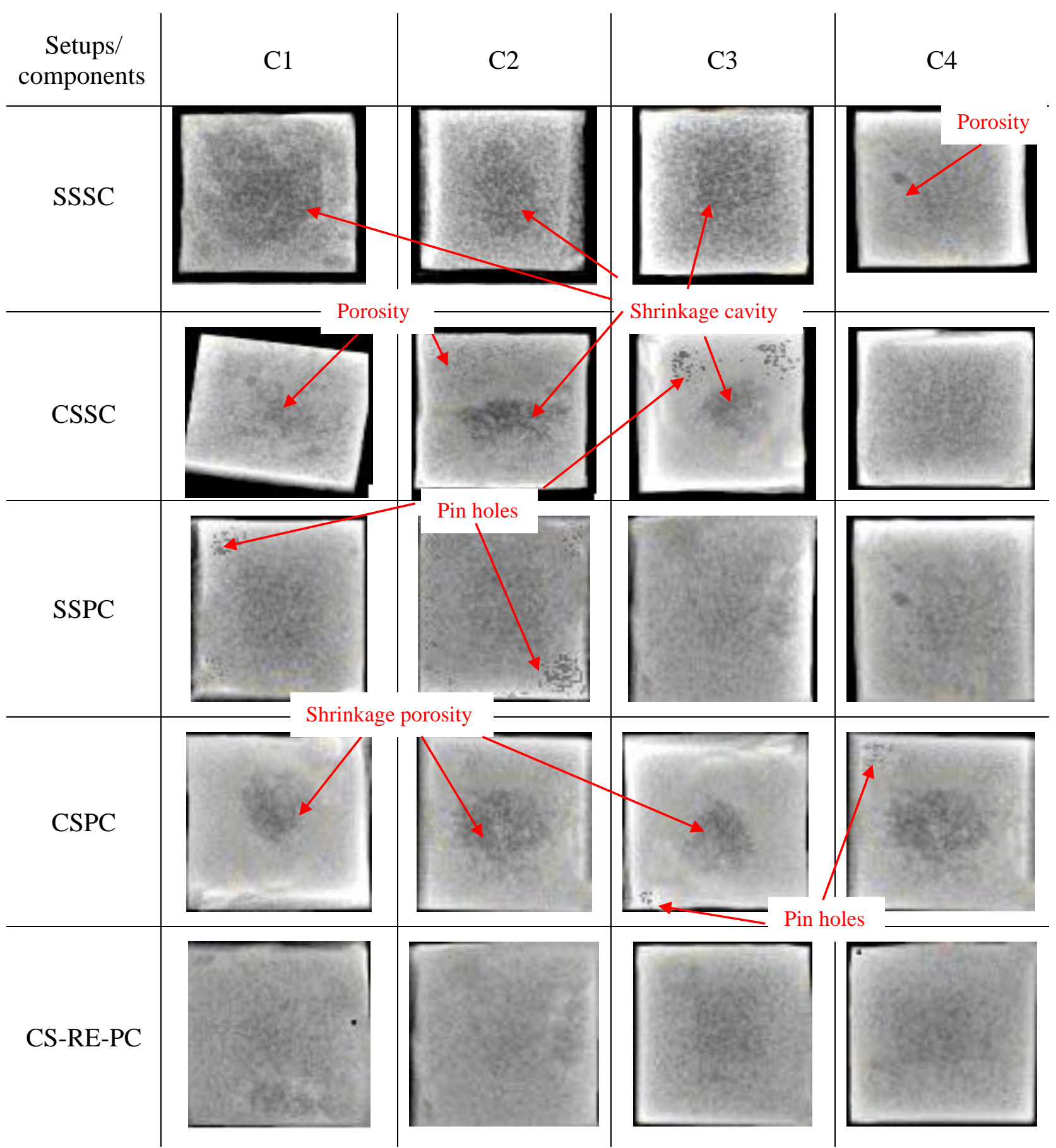

Fig. 12. X-ray micrographs of casting defects associated with the five mould set-ups/designs. 